\title{
O ensino da leitura e da literatura no ensino médio brasileiro: Controvérsias, diversidade e polifonia
}

\author{
Míria Gomes de Oliveira ${ }^{\mathrm{i}}$ \\ Universidade Federal de Minas Gerais, Brasil
}

\begin{abstract}
Resumo
Partindo da meta de universalização do atendimento à população de 15 a 17 anos (Meta 3 PNE/Brasil 2011-2020) e da proposição da Lei n. 11.741/2008, que integra ensino médio e educação profissional, retomamos a discussão sobre o ensino da literatura nessa etapa da educação básica, ressaltando a diversidade sócio-econômico-cultural dos sujeitos que a constitui. Para isso, defendemos a presença de obras canônicas e não-canônicas, baseando-nos no conceito de polifonia (Bakhtin, 1997) e nas características da "literatura menor" de Deleuze e Guattari (1977), em que a perspectiva da minoria é construída em uma "linguagem maior", designando a dimensão política e as condições revolucionárias de textos literários. Abre-se espaço de expressão a outras comunidades e forjam-se os meios para outras consciências e outras sensibilidades. Nosso principal objetivo é a construção de práticas de leitura menor e polifônicas em que o contato entre as vozes de professores e alunos e as vozes dos textos literários levem leitores a posicionamentos críticos.
\end{abstract}

Palavras-chave

Ensino da leitura e da literatura; Ensino médio; Diversidade e polifonia

\section{Introdução}

Dois fatos do cenário educacional brasileiro atual fazem com que a discussão em torno das orientações propostas ao ensino da leitura e da 
literatura em um dos principais documentos de parametrização curricular brasileiros - as Orientações Curriculares para o Ensino Médio (Brasil, 2006) seja aprofundada e reavaliada de forma mais incisiva no que se refere à antiga polêmica sobre a identidade pedagógica do ensino médio e o ensino da leitura e da literatura, nessa etapa da Educação Básica: $1^{\circ}$ ) a baixa taxa de atendimento aos jovens pelo ensino médio e as metas de expansão propostas pelo Plano Nacional de Educação, relativas à universalização do atendimento a toda população de 15 a 17 anos e à elevação da taxa líquida de matrículas para $85 \%$ nesta faixa etária (Meta 3 do PNE - Brasil 2011-2020); $2^{\circ}$ ) a proposição, da Lei n. 11.741/2008, da modalidade que integra ensino médio e educação profissional.

Ora, se por um lado, pela primeira vez, a população que historicamente sofre com a desigualdade - marca da divisão de bens simbólicos e materiais da sociedade brasileira - pode vislumbrar acesso ao ensino médio, por outro lado, o caráter profissionalizante deixa clara a preocupação com o mercado de trabalho, distanciando-se de uma proposta que valorize as identidades plurais de gênero, as variações linguísticas, as diversidades étnicas e culturais da juventude brasileira.

A proposição da lei supracitada não condiz com o ideal de universalização da lei como direito básico dos jovens até completarem 18 anos. A divisão de tempo nas grades curriculares pode comprometer o compromisso com uma formação humana, voltada para a formação de cidadãos, em detrimento da tecnicização, voltada para a formação de mão de obra para o mercado de trabalho do mundo do capital, que atualmente absorve grande parte dos jovens a partir dos 18 anos.

Neste texto, ressaltamos a importância de um currículo do ensino médio atento à diversidade e polifônico, comprometido com a formação de cidadãos, em detrimento da limitação técnica de formar profissionais para o mercado de trabalho. Ressaltamos, também, a dimensão política de todo o ato pedagógico em contexto escolar e suas implicações para o ensino da leitura e da literatura, a partir da ideia de "literatura menor" (Deleuze \& Guattari, 1977), tendo em vista uma prática de leitura menor e polifônica (Bakhtin, 1997). 


\section{O ensino da literatura e o currículo do ensino médio (EM)}

Aprofundar e reavaliar o currículo do ensino da literatura no momento em que políticas educacionais brasileiras buscam a universalização do EM requer a retomada de uma antiga polêmica sobre a identidade pedagógica e sua relação com o mundo do capital nessa etapa da educação básica.

O estudo realizado por Kuenzer (2011) aponta velhos problemas e novos desafios impostos pelo mundo capitalista que nos permitem uma compreensão ampla dos determinantes políticos-ideológicos que marcam o EM brasileiro. Suas reflexões apontam para a necessidade de repensar o currículo de modo a que o impacto dos problemas sociais do mundo dos estudantes seja considerado de forma radical e de forma a delinear suas causas históricas e suas determinações estruturais, como ponto de partida para a construção de alternativas (Kuenzer, 2011, p. 668). Além disso, chama a atenção para a necessidade de compreendermos as mudanças ocorridas no mundo do trabalho a partir de categorias de análise que permitam apreender as dimensões sociais e produtivas da prática pedagógica, de modo a identificar as novas demandas de educação e a que interesses elas se vinculam, com base em uma determinada concepção de sociedade (Kuenzer, 2011, p. 688).

Como Kuenzer (2011), assumimos a dimensão sócio-política de todo o ato pedagógico em contexto escolar, entendendo que o ensino da leitura e da literatura podem suscitar debates e levantar questionamentos sobre a realidade sócio-econômica e cultural do aluno, tanto no que se refere ao seu contexto local como ao nosso mundo global. A literatura é uma instituição social, um espaço privilegiado para emersão e expressão das "significações imaginárias", aqui compreendida, na esteira de Castoriadis (1999), como uma rede simbólica socialmente sancionada, em que se combinam, em proporções e em relações variáveis, um componente funcional e um componente imaginário, haja visto que cada sociedade constitui o conjunto de seu universo simbólico numa relação ambivalente com o histórico e com o imaginário.

No contexto brasileiro, as influências da concepção estruturalista da linguagem criaram raízes em gramáticas normativas e disseminaram modelos elitistas e descontextualizados de análise para a prática escolar, por detrás de uma pretensa neutralidade política do ensino da literatura. Neste momento em 
que buscamos a universalização da oferta para o ensino médio, questões políticas relacionadas ao capital e à diversidade cultural constitutiva de nossas sociedades complexas (Velho, 1994) devem ser debatidas tendo em vista a formação de leitores em contexto escolar.

Concordamos com Nagata (2008) ao afirmar que a recorrência de termos como significativa e autorizada, associados às produções artísticas e obras literárias apontadas nas OCEM (Brasil, 2006), corrobora a visão de que a literatura presente na escola necessita da legitimação de vozes de autoridade, como o tempo, no caso dos cânones, ou a crítica contemporânea, no caso de obras não-canônicas. Essa afirmação deixa ainda mais clara a interligação entre o ensino de textos literários em contextos marcados pela diversidade social e as implicações políticas do ensino da literatura. Em sala de aula, a prática de estudos dirigidos, questionários e roteiros de leitura, visando a inculcação de metalinguagens e aspectos formais do texto literário, deixava/deixa de fora a cultura e a produção de significados de alunos e professores. Esses, muitas vezes, silenciam-se diante das respostas prontas dos "manuais do professor" ou reproduzem modelos de análise literária em que foram formados, modelos igualmente elitistas e descontextualizados.

Essa concepção de ensino da leitura e da literatura tem feito com que vivências críticas de práticas de leitura sejam facilmente substituídas por uma prática pré-modelada nas gráficas editoriais. Sem negar a escolarização de qualquer texto, ao entrar em contexto escolar, questionamos antes, como se dá essa escolarização (Martins, 2003).

De uma perspectiva polifônica, a concepção de leitura pode potencializar o compromisso ético-político do ensino da literatura. Contudo, faz-se necessária uma ressalva: a questão da diferença cultural entre grupos sociais (Oliveira, 2000) resvalou na defesa, por parte de alguns grupos acadêmicos, de uma prática pedagógica em que o objetivo maior é o de fazerse ouvir apenas a voz dos grupos marginalizados e não o entrecruzamento de vozes, o diálogo polifônico que vimos defendendo. Esses grupos defendem o ensino apenas de obras não-canônicas. Acreditando que essa discussão envolve várias questões, destacaremos duas, sem negarmos sua complexidade: a escolha das obras e a prática escolar que medeia sua leitura.

Em relação à escolha, o ensino apenas de obras não-canônicas nos levaria aos mesmos erros e reproduziria os mesmos problemas que julga 
atacar, pois propõe também uma política separatista do ensino da literatura. No nosso entendimento, políticas separatistas podem ter, em última instância, consequências desastrosas por reforçarem preconceitos na visão do próprio grupo que os sofre. Dessa forma, a seleção de obras a serem ensinadas deve tomar como critério de escolha a diversidade que constitui o patrimônio literário da humanidade.

No momento histórico em que a diversidade é reafirmada como marca da identidade nacional brasileira, a formação de leitores deve refletir essa diversidade, considerando aspectos relativos a identidade, relações étnicoraciais e diversidade sociocultural. Dentre seus objetivos, está prevista a constituição de comunidades de leitores (Dionísio, 2000), crianças, jovens e/ou adultos, tendo em vista diálogos entre países que compartilham uma mesma língua e que possuem culturas diversas. Com isso, busca-se formas de superação das barreiras culturais que nos separam do outro, bem como estratégias que propiciem predisposição para a leitura positiva de nossa multiplicidade cultural e social.

Os multiculturalistas anti-essencialistas questionam a validade da natureza da realidade e da sociedade, dos processos psicológicos humanos, dos valores e princípios defendidos pelo discurso essencialista de críticos literários ortodoxos e colocam em dúvida a possibilidade de obras canônicas tradicionais terem alguma relevância para o leitor - sobretudo o leitor marginalizado - de hoje. Sem negar a pertinência da percepção de culturas historicamente postas à margem, silenciadas e invisibilizadas, faz-se necessária certa cautela em relação a um relativismo exacerbado sobre nossa condição humana. Essa cautela se justifica pela perda de referências que impossibilitam tomadas de posição e questionamentos críticos. Lembraria que os problemas políticos e éticos levantados por obras canônicas no Ocidente, infelizmente, não têm mudado. $O$ que tem mudado (e prefiro acreditar que este seja um fato a ser ressaltado positivamente) são as leituras feitas do cânone, como apontado por Will (1991), que ressalta os "perigosos" questionamentos instigados por abordagens inspiradas em reflexões sóciopolíticas. Certamente, ainda, teremos trabalhos como o de Bloom (1994), que prefere escrever uma "Elegia ao Cânone" em vez de perceber a vivacidade com que os estudos pós-estruturalistas criam relações entre nossa história passada e presente a partir da decanonização dos clássicos. Dessa forma, 
tanto os multiculturalistas anti-essencialistas quanto os críticos literários ortodoxos tornam-se presas do discurso da exclusão social que usa a diferença para justificar ideias separatistas. Essas, por sua vez, vêm a fundamentar práticas também separatistas e excludentes na escola.

Do ponto de vista de uma prática polifônica do ensino da literatura, a escola é vista como uma das principais instituições responsáveis pela transmissão do patrimônio cultural e literário da humanidade. O professor assume seu papel de mediador e busca caminhos através dos quais a formação do leitor ocorra de forma prazerosa e crítica. As práticas de leitura não podem se restringir à consecução de tarefas obrigatórias ou finalistas, como o Exame Nacional de Ensino Médio (ENEM), que produzem o efeito retroativo nos currículos, práticas de leitura e avaliações ao longo dessa etapa da educação básica. Muitas vezes, em nome dessa obrigatoriedade, a prática de ensino em sala de aula restringe o ensino da gramática a aspectos estruturais da língua e deixa de lado o ensino da literatura e as discussões críticas suscitadas pelo texto literário.

Nesse cenário, a presença de textos canônicos e não-canônicos no ensino médio brasileiro só pode ser defendida tendo em vista uma concepção de leitura baseada nas idéias de que ler é produzir conhecimento e de que um texto literário é construído como um infinito mosaico de citações, influências e vozes histórico-sociais. Nas palavras de Bakhtin (1988):

Em cada época de sua existência histórica a obra é levada a estabelecer contatos estreitos com a ideologia cambiante do cotidiano, a impregnar-se dele e alimentar-se da seiva nova secretada. É apenas na medida em que a obra é capaz de estabelecer um vínculo orgânico ininterrupto com a ideologia do cotidiano de uma determinada época, que ela é capaz de viver nesta época (é claro, nos limites de um grupo social determinado) (p. 119).

A abordagem de uma obra literária envolve, por um lado, os sentidos criados na interação texto/leitor e, por outro lado, a dimensão formal que estrutura sua composição. Significação e construção, como já apontado por Paulino (2004), são aspectos devem ser considerados nas práticas de letramento literário escolar. $O$ ensino de obras canônicas e não-canônicas não se justifica apenas em nome de um senso estético eleito a partir da visão elitista que pretende separar crítica social e literária, negando relações entre literatura e a possibilidade de educação democrática. Discordamos de afirmações como a de Bloom (1994) que acredita que: 
Crítica cultural é uma outra ciência social. Mas a crítica literária, como uma arte, sempre será um fenômeno elitista. É um erro acreditar que a crítica literária poderia se tornar uma base para a educação democrática ou para melhorias sociais (p. 17).

Diante dessas considerações, podemos inferir que a dimensão subversiva do ensino da literatura pode pôr em risco o privilégio, restrito às classes economicamente favorecidas, de usufruir de uma literatura firmada em padrões estéticos próprios, como um traço de distinção social (Bourdieu, 2007). Por isso, a escolha de textos literários deve ocorrer a partir da sugestão de obras indicadas por alunos, professores e programas oficiais.

Uma alternativa a essa visão elitista do ensino da literatura é discutida por Deleuze e Guattari (1977), ao apontarem aspectos que caracterizam uma "literatura menor". Para esses autores, a "literatura menor" tem três características básicas:

1. Ela não é construída dentro de uma "linguagem menor", como são preconceituosamente consideradas as variantes da língua padrão. Ela é, antes, aquela em que uma minoria constrói em uma "linguagem maior". Uma linguagem que desterritorializa o próprio conceito de língua e que é utilizada para subverter. A literatura menor é, em si mesma, a possibilidade de estabelecer uma prática menor da linguagem maior, permitindo a escuta da voz da cultura dominante e da cultura dos socialmente marginalizados, da cultura popular.

2. Tudo nela é político. O social milieu deixa de ser pano de fundo para assumir o proscênio. Ela não designa literaturas específicas, mas as condições revolucionárias de toda a literatura dentro do cerne do que é chamada grande (ou estabelecida) literatura (p. 68).

3. Tudo nela assume um valor coletivo. Diferente do ceticismo relativista, ela produz solidariedade ativa. Com isto, abre-se espaço de expressão a outras comunidades e forjam-se os meios para outras consciências e outras sensibilidades, assim como o cão de "Investigações" (de Kafka), que reclama por uma outra ciência (p. 67). 
A literatura menor faz uso do multilinguismo de sua própria língua, faz parte dele, opõe a condição oprimida à condição opressora. Procura pontos de não-cultura, zonas linguísticas através das quais uma língua pode escapar. "Um animal" entra nas coisas, um conjunto de vozes vem à tona. Ela acontece quando estilos, gêneros ou movimentos literários, mesmo aqueles bem menores, compartilham apenas um sonho: saber criar o sonho oposto, saber criar um vir a ser menor (Deleuze \& Guattari, 1977, p. 71)

A visão de literatura menor destaca o lado político na própria edificação da obra literária e, consequentemente, no trabalho teórico que vem a discutila. Negar o caráter político de todo empreendimento teórico tem sido a máscara retórica de posicionamentos que dão origem a práticas educacionais elitistas.

Todas essas considerações nos levam a pensar em uma leitura menor do texto literário, uma prática de leitura aberta às zonas linguísticas e às interpretações multiculturais de textos literários. Com a leitura menor, abrir espaço aos eixos periféricos, às vozes e dialetos dos alunos presentes em salas de aula polifônicas, tornando evidentes as múltiplas formas de interpretação dos estudantes do ensino médio, desafiando-os a traçar significados e a encontrar prazer em suas próprias leituras, marcadas pela lente da juventude.

\section{Leitura menor e polifonia}

O ensino da literatura comprometido com a diversidade social busca garantir espaço às múltiplas vozes presentes em uma sala de aula que é vista como constitutivamente conflituosa, uma arena na qual as vozes presentes no texto literário, as vozes dos alunos e dos professores se cruzam. A visão polifônica vê, nesse entrecruzamento, o momento central do processo de aprendizagem, pois é neste momento que o contato com as diferentes vozes do poder pode causar estranhamentos que levam o sujeito-leitor a deslocamentos e posicionamentos críticos.

O conceito de polifonia torna-se um fundamento ético em aulas de ensino da literatura porque permite ver a linguagem como constitutivamente diversificada em todo e qualquer momento de sua existência histórica: a totalidade do mundo de objetos e idéias na linguagem representados é 
expressa através da diversidade social dos tipos de fala e pela diferenciação assumida nas vozes individuais. Essa diversidade constitui a polifonia, a presença de várias vozes sociais em torno de uma mesma enunciação. 0 contato entre diferentes vozes permite grande variedade de ligações e interrelações estilísticas que dialogam entre si. Há múltiplas formas de representar a realidade devido ao caráter heterogêneo constitutivo da linguagem (Bakhtin, 1997, p. 98).

Toda a enunciação se realiza em um campo em que forças centrípetas e centrífugas se interceptam, ou melhor, toda a enunciação é parte da "linguagem unitária" (que faz com que ela aconteça e que a estrutura em seu momento, sua força centrípeta) e, ao mesmo tempo, participa ativamente da plurivocidade social e histórica que a rodeia (suas forças centrífugas) (Bakhtin, 1988, p. 83). Do ponto de vista das tendências conservadoras da linguagem, a palavra é reconhecida como auto-suficiente e completa, e não como um potencial de fala. A visão estruturalista e monológica da linguagem diminui a importância das forças centrífugas e da variação de sentidos de uma palavra em diferentes contextos. A palavra monológica exclui leituras responsivas, e se assujeita às forças centrípetas do poder hegemônico. Em uma concepção dialógica e polifônica, a palavra enquanto simples potencialidade sai à procura de seu objeto e só encontra resistência no próprio objeto, ou seja, na impossibilidade de ele ser completamente dito pela linguagem. A forma como a palavra concebe seu objeto é melhor explicada usando-se a metáfora do raio de luz:

Se imaginarmos a intenção de uma palavra, isto é, seu direcionamento ao objeto, na forma de um raio de luz, então o jogo vivo e irrepetível de cores e luz nas facetas de uma imagem que ele constrói pode ser explicado como uma dispersão espectral de uma palavra-raio, não dentro do objeto nele mesmo... mas como sua dispersão espectral em uma atmosfera cheia de palavras alheias, julgamentos de valor e sotaques através dos quais o raio passa em sua direção ao objeto; a atmosfera social da palavra, a atmosfera que envolve o objeto, faz com que as facetas da imagem se dispersem (Bakhtin, 1988, p. 87).

A intenção da palavra em direção a seu objeto se dispersa ao entrar em contato com seu ambiente. A produção e compreensão de um enunciado ocorrem no contexto dos enunciados que o precederam e no contexto dos enunciados que o seguem. O enunciado dialoga com seu meio, reflete e refrata seu redor. Este é o princípio do dialogismo: a relação necessária de 
qualquer enunciação com outras enunciações. A palavra encontra em seu caminho na direção do objeto em questão um ambiente dialógico cheio de tensões e inter-relações. Ela vem à tona com algumas, filia-se a outras, nega tantas outras. Não é presa a um significado fixo, mas definido em seu contexto. Tudo isto dá forma ao discurso, deixa marcas em seus aspectos semânticos. Uma enunciação, em um dado momento histórico particular, não pode apagar as marcas sócio-ideológicas de seu ambiente, não pode deixar de se tornar participante ativa do diálogo social.

A tomada de posição de alunos e professores diante de textos literários, ou melhor, suas atitudes responsivas (Bakhtin, 1997, p. 67), efetiva a escuta da polifonia, sempre latente. A polifonia é a escuta de nossa indignação cotidiana perante relações de poder injustas que vemos acontecer diariamente. É a voz da "segunda vida", da "segunda cultura", sustentada pelas pessoas comuns, que se opõe à voz dominante "oficial". Sua denúncia é o destronamento da falsa ordem que se mantém pela força e pela ilegitimidade.

A voz de um aluno não representa apenas a sua voz. Como dito por Lensmire (1994, p. 3), ao compreendermos a experiência social, nos compreendemos a nós mesmos. A voz de cada aluno traz consigo a voz de sua comunidade, a voz da indignação e da resistência, caracterizando a polifonia. Em uma sala de aula polifônica, alunos e professores relacionam seus horizontes sociais aos horizontes sociais de textos literários, fazendo presente, a partir da compreensão do enunciado do texto, sua interpretação. Estaríamos, assim, diante de um duplo movimento que demonstra a forma como a palavra conceitua seu objeto: por um lado, o objeto é salientado, destacado; por outro lado, é submerso na opinião social heteroglóssica, por palavras alheias a ele - pelo outro.

A forma como as vozes são arranjadas, ressaltadas ou silenciadas é que faz o discurso da sala de aula ser polifônico ou não. Inicialmente usada por Bakhtin para caracterizar a construção das vozes das personagens e narradores no romance, a polifonia se dá quando a voz destes existe em um mesmo plano, quando eles têm direitos iguais de se pronunciarem, assim como no segmento acima. Ela se refere à autonomia das vozes das personagens (Vice, 1997, p. 112). 
Muitas vezes confundido como sinônimo de dialogismo, o conceito de polifonia está ligado às estratégias discursivas acionadas, enquanto que o dialogismo é o princípio constitutivo da linguagem e de todo o discurso. Segundo Barros (1994):

Os textos são dialógicos porque resultam do embate de muitas vozes sociais; podem, no entanto, produzir efeitos de polifonia, quando essas vozes ou algumas delas deixam-se escutar, ou de monofonia, quando o diálogo é mascarado e uma voz, apenas, faz-se ouvir (p. 6).

Ao contrário de uma visão que entende a voz do professor apenas como a imposição de uma "única interpretação possível", a presença da voz do professor não só garante um outro olhar mas também instiga o pronunciamento da voz dos alunos. Essa visão pode, ainda, nos ajudar a diferenciar procedimentos opressorese autoridade necessária. Seria ilusão deixar de perceber o poder dos educadores nos processos interativos de sala de aula e na compreensão dos textos, isto é, a autoridade textual que vem a legitimar uma prática discursiva particular (Giroux, 1990). O importante é discutir como se dá a prática dessa autoridade, pois produz e constitui formas de interesses políticos, éticos e sociais.

Nesse ponto, queremos salientar que a autoridade textual do professor pode ou não ser utilizada para orientar os alunos na produção de uma leitura menor de textos literários canônizados ou marginalizados. A prática da autoridade textual produz, por si mesma, práticas de leitura: ela pode (ou não) garantir que os estudantes venham (ou não) a desafiar a própria noção e transmissão do conhecimento na escola. A prática que quer chamar a atenção à voz dominante e à voz do outro historicamente marginalizado, a partir da ênfase nas relações ideológicas e de poder no texto, deve buscar também procedimentos que configurem, eles mesmos, práticas de diálogo. Por isso, concordamos com Arrojo (1994) ao ponderar que o professor:

(...) não abrirá mão de sua "autoridade textual", mas se empenhará em torná-la transparente, mostrando a seus alunos que esse tipo de autoridade, como qualquer outra, dentro ou fora da instituição escolar, é uma forma de poder que pode ser conquistada (p. 105).

Neste jogo de inter-relações, os sujeitos de uma sala de aula podem vir a assumir posições heterogêneas e contraditórias. No entanto, perceber a unidade dialética de continuidade e ruptura de nossa prática pedagógica nos 
faz questionar a importância que devemos dar a nossas atitudes e representações, para que o trabalho que se quer inovador e subversivo não seja limitado pelas funções institucionalmente internalizadas e legitimadas.

Considerando letramento como um fenômeno político, as práticas linguísticas e as formas de conhecimento que ele favorece não podem ser entendidas fora das relações de poder que estruturam a sociedade mais ampla. O contato com estas relações de poder, ou melhor, o contato com as vozes do poder, sejam elas a literatura canônica, a linguagem padrão ou mesmo a voz da autoridade do professor e até de outros colegas, é fundamental para que os alunos leiam não apenas diferentes textos mas, também, para que leiam criticamente qualquer texto. Para que desenvolvam uma reflexão dialética da realidade e interroguem a complexidade de suas próprias histórias. Enfim, para que resistam. Resistir é um dos princípios centrais de nossa visão de leitura menor.

\section{Considerações finais}

Neste texto, problematizamos questões que interligam o ensino da literatura no ensino médio brasileiro ao mundo do capital e a controvérsias da crítica literária, tendo em vista a ampliação de uma proposta de ensino da literatura comprometido com a diversidade social e com práticas dialógicas e polifônicas em aulas de leitura. Para isso, discorremos sobre a visão de literatura menor de Deleuze e Guattari (1977), aquela em que uma minoria constrói em uma "linguagem maior", em que a linguagem desterritorializa o próprio conceito de língua e que é utilizada para subverter, permitindo a escuta da voz da cultura dominante e da cultura dos socialmente marginalizados, da cultura popular. Discorremos, também, sobre uma prática de leitura menor e polifônica em sala de aula, comprometida com a diversidade social brasileira, principalmente no momento em que buscamos atender a parcela da população que historicamente tem tido seu direito ao ensino médio negado.

Nessa perspectiva, o trabalho com textos canônicos e não-canônicos é orientado pela liberdade de exercer nossa capacidade crítica diante de todo e qualquer texto literário. E é por isso que a presença de textos canônicos e não-canônicos no ensino médio brasileiro só pode ser defendida, como já foi 
referido, almejando uma concepção de leitura que se fundamente no princípio de que ler é produzir conhecimento e, mais, de que um texto literário é, conforme anteriormente mencionado, um infinito mosaico de citações, influências e vozes histórico-sociais.

\section{Referências}

Arrojo, R. (1994). Ensino, conscientização política e pós-modernismo. Trabalhos em Lingüística Aplicada, 23, 97-106.

Bakhtin, M. (1988). Questões de literatura e de estética. São Paulo: Hucitec.

Bakhtin, M. (1997). Estética da criação verbal. São Paulo: Hucitec.

Barros, D. (1994). Dialogismo, polifonia e enunciação. In D. Barros \& J. Fiorin, Dialogismo, polifonia, intertextualidade em torno de Bakhtin (pp. 4-11). São Paulo: Edusp.

Bloom, H. (1994). The Western Canon. New York: Harcourt Brace e Company.

Bourdieu, P. (2007). A distinção: Crítica social do julgamento. São Paulo: Edusp; Porto Alegre, RS: Zouk.

Brasil (2006). Orientações curriculares nacionais para o ensino médio. Volume 1: Linguagens, códigos e suas tecnologias. Brasília: MEC/SEB. Disponível em: http://portal.mec.gov.br/seb/arquivos/pdf/linguagens02.pdf (acesso em $15 \mathrm{de}$ maio de 2012).

Castoriadis, C. (1999). Feito e a ser feito. As encruzilhadas do labirinto $V$. Rio de Janeiro: DP\&A Editora.

Deleuze, G., \& Guattari, F.(1977). Kafka: Por uma literatura menor. Rio de Janeiro: Imago.

Dionísio, M. L. (2000). A construção escolar de comunidades de leitores: Leituras do manual de Português. Coimbra: Almedina.

Giroux, H. (1990). Reading texts, literacy, and textual authority: Voice and the politics of identity. Journal of Education, 172(1), 84-103.

Kuenzer, A. Z. (2011). A formação de professores para o ensino médio: Velhos problemas, novos desafios. Educação e Sociedade, 32(116), 667-688.

Lensmire, T. J. (1994). Writing workshop as carnival: Reflections on an alternative learning environment. Harvard Educational Review, 64(4), 371-392.

Martins, A. A. (Orgs.). (2003). A escolarização da leitura. Belo Horizonte: Autêntica.

Nagata, A. A. (2008). Multiculturalismo e literatura: As fronteiras do currículo oficial. Rumores, 2(3), s/ pág. Disponível em: http://www.rumores.usp.br/artigos2.asp? cod_atual $=75$

Oliveira, M. G. (2000). Shakespeare no subúrbio: Crítica, polifonia e carnaval na aula de leitura (Dissertação de Mestrado). Campinas - SP, Brasil, Unicamp. 
108 Míria Gomes de Oliveira

Paulino, G. (2004). Formação de leitores: A questão dos cânones literários. Revista Portuguesa de Educação, 17, 42-63.

Velho, G. (1994). Projeto e metamorfose. Antropologia das sociedades complexas. Rio de Janeiro: Jorge Zahar.

Vice, S. (1997). Introducing Bakhtin. Manchester: Manchester University Press.

Will, G. (1991). Literary politics. In D. Richter, Falling into theory. Conflicting views on reading literature. Boston: Bedford Books of St. Martin's Press. 
TEACHING READING AND LITERATURE IN BRAZILIAN SECONDARY SCHOOLS: CONTROVERSIES, DIVERSITY AND POLYPHONY

\begin{abstract}
Based on the goals of universal attendance across the population aged 15 to 17 (Goal 3 from the Plano Nacional de Educação - Brazil 2011-2020) and on the proposal of Law nr. 11.741/2008, which integrates secondary education and professional education, we review the discussion about the curriculum for this stage of primary education, highlighting the teaching of literature in its political dimension. Thus, we revisit the debate around the teaching of canonical and non-canonical works in secondary education curriculum, beginning with the basic features of "minor literature" (Deleuze \& Guattari, 1977). Our objective is to discuss minor and polyphonic reading practices (Bakhtin, 1997) as a means to promote interactions among the voices of teachers and students and the voices of power of the literary texts, creating a critical stance in the readers.
\end{abstract}

Keywords

Teaching reading and literature; Secondary schools; Diversity and polyphony

\title{
LA ENSEÑANZA DE LA LECTURA Y DE LA LITERATURA EN LA EDUCACIÓN SECUNDARIA EN BRASIL: CONTROVERSIAS, DIVERSIDAD E POLIFONÍA
}

\section{Resumen}

Partiendo del objetivo de la universalización de los servicios de educación a la población de 15 a 17 años (objetivo 3 PNE/Brasil 2011-2020) y de la proposición de la Ley n. 11.741/2008, que integra la educación secundaria, retomamos el debate sobre la enseñanza de la literatura en esta etapa de la educación básica, destacando la diversidad socio-económico-cultural de los individuos que la constituyen. Para eso, defendemos la presencia de obras canónicas y no canónicas, basándonos en el concepto de polifonía (Bakhtin, 


\section{Míria Gomes de Oliveira}

1997) y en las características de la "baja literatura" de Deleuze y Guattari (1977), en que la perspectiva de la minoría se construye en un "lenguaje mayor" designando la dimensión política y las condiciones revolucionarias de los textos literarios. Se abre espacio para la expresión de otras comunidades y se forman los medios para otras mentes y otras sensibilidades. Nuestro principal objetivo es la construcción de prácticas de lectura baja y polifónicas, donde el contacto entre las voces de los profesores y de los estudiantes y las voces de los textos literarios conduzcan los lectores a posicionamientos críticos.

\section{Palabras-clave}

Enseñanza de la lectura y de la literatura; Educación secundaria; Diversidad e polifonía 